DANTAS, H. da S. et al. Estudo de viabilidade técnica da aplicação do método sísmica de refração para otimização de prováveis obras de ampliação do IFMG - Campus avançado Piumhi

\title{
ESTUDO DE VIABILIDADE TÉCNICA DA APLICAÇÃO DO MÉTODO DE SÍSMICA DE REFRAÇÃO PARA OTIMIZAÇÃO DE PROVÁVEIS OBRAS DE AMPLIAÇÃO DO IFMG - CAMPUS AVANÇADO PIUMHI
}

\author{
Hiago da Silva Dantas ${ }^{1}$ \\ Marina Vieira Funchal Guimarães ${ }^{2}$ \\ Stella Maria Gomes Tomé ${ }^{3}$ \\ Marina Martins Araújo ${ }^{4}$ \\ Felipe da Silva Alves 5
}

\begin{abstract}
RESUMO
O estudo do comportamento do solo é de grande importância para a Engenharia Civil, visto que qualquer edificação interage com a superfície terrestre. Desta forma, o método geofísico denominado sísmica de refração pode fornecer informações relevantes para o entendimento sistêmico da subsuperficie, de modo a complementar dados de investigações diretas, que são pontuais. O presente trabalho tem como objetivo estudar a viabilidade técnica de aplicação do método de sísmica de refração para otimização de prováveis obras de ampliação do IFMG Campus Avançado Piumhi. Foram obtidas informações a respeito da prática de execução do referido método de prospecção e de características do subsolo local, do prédio atual e de prováveis instalações do Campus. Esses dados foram analisados qualitativamente e forneceram embasamento para o estudo de viabilidade técnica. Concluiu-se que a aplicação da técnica de levantamento por sísmica de refração nas áreas de estudo é viável tecnicamente, podendo, assim, contribuir para elaboração de um perfil praticamente contínuo das interfaces entre as camadas de solo, bem como para o mapeamento do lençol freático. Para orientar possíveis aplicações da técnica de sísmica de refração nas áreas de estudo, foi sugerida uma programação de prospecção por este método no local.
\end{abstract}

Palavras-chave: Sísmica de Refração. Método Indireto de Prospecção. Viabilidade Técnica.

\footnotetext{
${ }^{1}$ Graduando em Engenharia Civil pelo Instituto Federal de Minas Gerais (IFMG) - Campus Piumhi.

E-mail: dantashiago@gmail.com.

${ }^{2}$ Graduanda em Engenharia Civil pelo Instituto Federal de Minas Gerais (IFMG) - Campus Piumhi. E-mail: marina.vf.guimaraes@gmail.com.

${ }^{3}$ Mestre em Economia Doméstica pela Universidade Federal de Viçosa(UFV). Professora do ensino básico, técnico e tecnológico do Instituto Federal Minas Gerais - Campus Piumhi. E-mail: stella.tome@ifmg.edu.br.

${ }^{4}$ Pós-graduada em Orientação, Supervisão e Inspeção Escolar pela Universidade Cidade de São Paulo. Graduada em Letras pela Universidade de Uberaba. Professora do Instituto Federal Minas Gerais - campus São João Evangelista. E-mail: marina.araujo@ifmg.edu.br.

5 Doutorando em Engenharia na Universidade Federal do Rio de Janeiro. Mestre em Engenharia Civil pela Universidade Federal do Rio de Janeiro. E-mail: felipe.alves@ifmg.edu.br.
}

ForSci.: r. cient. IFMG, Formiga, v. 4, n. 1, p. 63-81, jan./jun. 2016. 


\section{FORSCIENCE}

DANTAS, H. da S. et al. Estudo de viabilidade técnica da aplicação do método sísmica de refração para otimização de prováveis obras de ampliação do IFMG - Campus avançado Piumhi

\section{INTRODUÇÃO}

A Engenharia Civil acompanhou e foi determinante no desenvolvimento das civilizações durante séculos. Com isso, o homem teve de lidar com os mais diversos problemas, dentre os quais se destaca o desconhecimento do comportamento do solo.

Uma série de acidentes ocorridos em grandes obras de engenharia, ao fim do século XIX e início do século XX, fomentou o estudo do solo, sua compreensão e manipulação, uma vez que qualquer edificação interage com a superfície terrestre, estando ela em contato direto ou não com a mesma. Citam-se, como exemplos, os sucessivos escorregamentos de terra de Culebra e Cucaracha durante e após a construção do Canal do Panamá, que por vezes bloquearam a passagem de embarcações (CAPUTO, 2014).

A ciência geofísica tem contribuído de forma significativa para o conhecimento do subsolo. Segundo Kearey, Brooks e Ian (2009), os métodos geofísicos de prospecção do terreno, embora passíveis de ambiguidades e incertezas na interpretação, podem fornecer informações relevantes para o entendimento sistêmico do comportamento do solo, de modo a complementar os dados das investigações diretas, que são pontuais. Como exemplos dessas informações, citam-se a estratigrafia do terreno, os prováveis tipos de solo e/ou rocha, a profundidade do lençol freático, bem como eventuais interferências subterrâneas (tubulações, eletrodutos, fundações pré-existentes, etc.) presentes no subsolo (AZEVEDO, 2010; BARSÉ et al., 2010).

O presente trabalho tem como objetivo estudar a viabilidade técnica de aplicação do método geofísico denominado sísmica de refração para otimização de obras de ampliação do Instituto Federal de Educação, Ciência e Tecnologia (IFMG) Campus Avançado Piumhi. Caso esta viabilidade seja confirmada, o levantamento por sísmica de refração poderá contribuir para elaboração de perfis geotécnicos do terreno onde se pretende construir novos prédios que possam comportar salas de aula, laboratórios, áreas de lazer e recreação.

A escolha do referido método geofísico se deve à sua ampla aplicação em projetos de Engenharia Civil, no que diz respeito à investigação do subsolo e ainda, de acordo com Herzig (2004, p. 4), por fornecer "uma imagem detalhada das estruturas em subsuperfície, podendo apresentar boa resolução e grande penetração”. 


\section{FORSCIENCE}

DANTAS, H. da S. et al. Estudo de viabilidade técnica da aplicação do método sísmica de refração para otimização de prováveis obras de ampliação do IFMG - Campus avançado Piumhi

O estudo supracitado possui abordagem qualitativa. Para a coleta de informações, foi utilizada análise documental e entrevistas semiestruturadas ${ }^{6}$, de forma a averiguar os dados relativos à obtenção de características do terreno, do prédio atual e de prováveis instalações do Campus.

\section{REFERENCIAL TEÓRICO}

A técnica de sísmica de refração encontra-se explicitada resumidamente a seguir.

\subsection{O método de sísmica de refração}

De acordo com Kearey, Brooks e Ian (2009), no método de sísmica de refração, as ondas sísmicas são geradas por uma fonte controlada e se propagam em subsuperfície. Algumas delas retornam à superfície após sofrerem refração nas interfaces entre as camadas geológicas em profundidade, podendo ser detectadas por instrumentos distribuídos ao longo do terreno, os quais registram as vibrações do solo e os tempos de chegada a diferentes distâncias em relação à fonte. Assim, os tempos de percurso das ondas são convertidos em valores de profundidade, mapeando as interfaces geológico-geotécnicas.

\subsection{Ondas sísmicas}

As ondas sísmicas são de baixa energia e curta duração, propagadas em todas direções na forma de pulsos a partir de uma fonte sísmica. A passagem destas através de um sólido não altera a massa do material, por isso são denominadas ondas elásticas de corpo (TEIXEIRA, 2013).

Segundo Azevedo (2010), as ondas de corpo podem ser divididas em: ondas P, que se propagam longitudinalmente, e ondas $\mathrm{S}$, de propagação transversal. Para fins de engenharia, tem-se maior aplicação da sismologia de ondas de cisalhamento (ou ondas S), nas quais as medidas das velocidades para camadas mais próximas à superfície permitem o cálculo do coeficiente de Poisson, que, de acordo como Kearey, Brooks e Ian (2009), é um indicador litológico o qual fornece informações sobre as propriedades geotécnicas do terreno.

6 Segundo Flick (2004), entrevista semiestruturada é aquela em que o entrevistado possui amplo conhecimento sobre o tópico em estudo. Para a obtenção de informações o entrevistador utiliza um roteiro previamente estabelecido, complementando com outras questões inerentes às circunstâncias momentâneas à entrevista. 


\subsection{Sistema de aquisição de dados sísmicos}

De acordo com Chiossi (2013), o sistema de aquisição de dados deve ser constituído pelos seguintes instrumentos: uma fonte sísmica repetível, geofones e um sismógrafo multicanal.

Kearey, Brooks e Ian (2009) descrevem fonte sísmica como uma região localizada, dentro da qual a repentina liberação de energia gera ondas mecânicas. Estas ondas são captadas pelos geofones e registradas pelo sismógrafo, que grava o tempo decorrido entre a liberação da energia e a chegada da primeira onda P.

Essas informações são processadas utilizando-se pacotes de softwares computacionais, que identificam e realizam automaticamente o mapeamento das camadas componentes do solo estudado (KEAREY; BROOKS; IAN, 2009).

\section{METODOLOGIA}

Foram obtidos junto à empresa especializada na área dados a respeito da prática de execução do método de sísmica de refração e dados referentes às características do subsolo local, do prédio atual, bem como prováveis instalações do IFMG - Campus Avançado Piumhi.

Para levantamento das informações supracitadas, foram realizadas três entrevistas semiestruturadas:

a) a primeira foi efetuada em Piumhi-MG, em 10 de junho de 2015, com o então Diretor de Ensino, Pesquisa e Extensão do IFMG - Campus Avançado Piumhi, professor Humberto Coelho de Melo e abordou ideias preliminares de prováveis obras de ampliação do campus associadas ao projeto anterior à construção do prédio atual (ver apêndice A: entrevista semiestruturada A);

b) a segunda, concretizada em Piumhi-MG, em 16 de outubro de 2015, foi aplicada ao engenheiro civil Sr. Nivaldo Alves de Oliveira, responsável técnico pelo projeto e execução da obra de construção da edificação existente no Campus e resultou em dados sobre a estratigrafia do terreno, a terraplenagem e o projeto de fundações do prédio atual (ver apêndice B: entrevista semiestruturada B);

c) a terceira, realizada em São Paulo-SP, em 26 de outubro de 2015, foi 


\section{FORSCIENCE}

DANTAS, H. da S. et al. Estudo de viabilidade técnica da aplicação do método sísmica de refração para otimização de prováveis obras de ampliação do IFMG - Campus avançado Piumhi

direcionada ao geofísico Sr. Wagner França Aquino, responsável técnico pela empresa GPR Geofísica Ltda., e forneceu informações referentes à prática de execução do levantamento por sísmica de refração (ver apêndice C: entrevista semiestruturada C).

As informações coletadas foram analisadas por meio do método de pesquisa qualitativa $^{7}$, de forma a embasar o estudo de viabilidade técnica que é realizado no tópico seguinte.

\section{ESTUDO DE VIABILIDADE TÉCNICA}

De acordo com Shull et al. (2004), o objetivo principal de um estudo de viabilidade não é encontrar uma resposta definitiva, mas sim criar um corpo de conhecimento sobre a aplicação da tecnologia. Neste sentido, estuda-se a viabilidade da aplicação do método de sísmica de refração nas áreas remanescentes do IFMG - Campus Avançado Piumhi, isto é, se o mesmo atende de forma satisfatória aos objetivos inicialmente definidos. Para tanto, é necessária uma descrição dos objetos de estudo sob o ponto de vista técnico, localizando-os geograficamente e identificando suas características mais relevantes.

\subsection{Caracterização do terreno}

\subsubsection{Situação Geográfica}

As áreas de estudo do presente trabalho estão localizadas na porção norte do município de Piumhi, situado na mesorregião oeste do Estado de Minas Gerais, a 256Km de Belo Horizonte. A cidade de Piumhi possui cerca de 31.883 habitantes. Sua economia se destaca na produção agrícola bem como de produtos como café, milho, feijão e leite, assim como em atividades ligadas à pecuária, comércio e serviços (IBGE, 2010).

Conforme apresentado na figura 3.1 a seguir, as áreas de estudo estão situadas junto ao IFMG - Campus Avançado Piumhi, localizado na Rua Severo Veloso, 1.880, esquina com a Avenida José Alvarenga Peixoto, próximo ao Poliesportivo Municipal Totinha

\footnotetext{
7 “A pesquisa qualitativa parte da noção da construção social da realidade em estudo, está interessada nas perspectivas dos participantes, em suas práticas do dia a dia e em seu conhecimento cotidiano em relação a questão em estudo." (FLICK, 2009).
} 


\section{FORSCIENCE}

DANTAS, H. da S. et al. Estudo de viabilidade técnica da aplicação do método sísmica de refração para otimização de prováveis obras de ampliação do IFMG - Campus avançado Piumhi

Rezende, no Bairro Nova Esperança, Piumhi-MG. A área de estudo 1 possui cerca de 5.324 $\mathrm{m}^{2}$, perímetro em torno de $310 \mathrm{~m}$, e encontra-se em frente ao prédio existente. A área de estudo 2 tem, aproximadamente, $14.000 \mathrm{~m}^{2} \mathrm{e} 490 \mathrm{~m}^{2}$, localizando-se à direita do prédio atual.

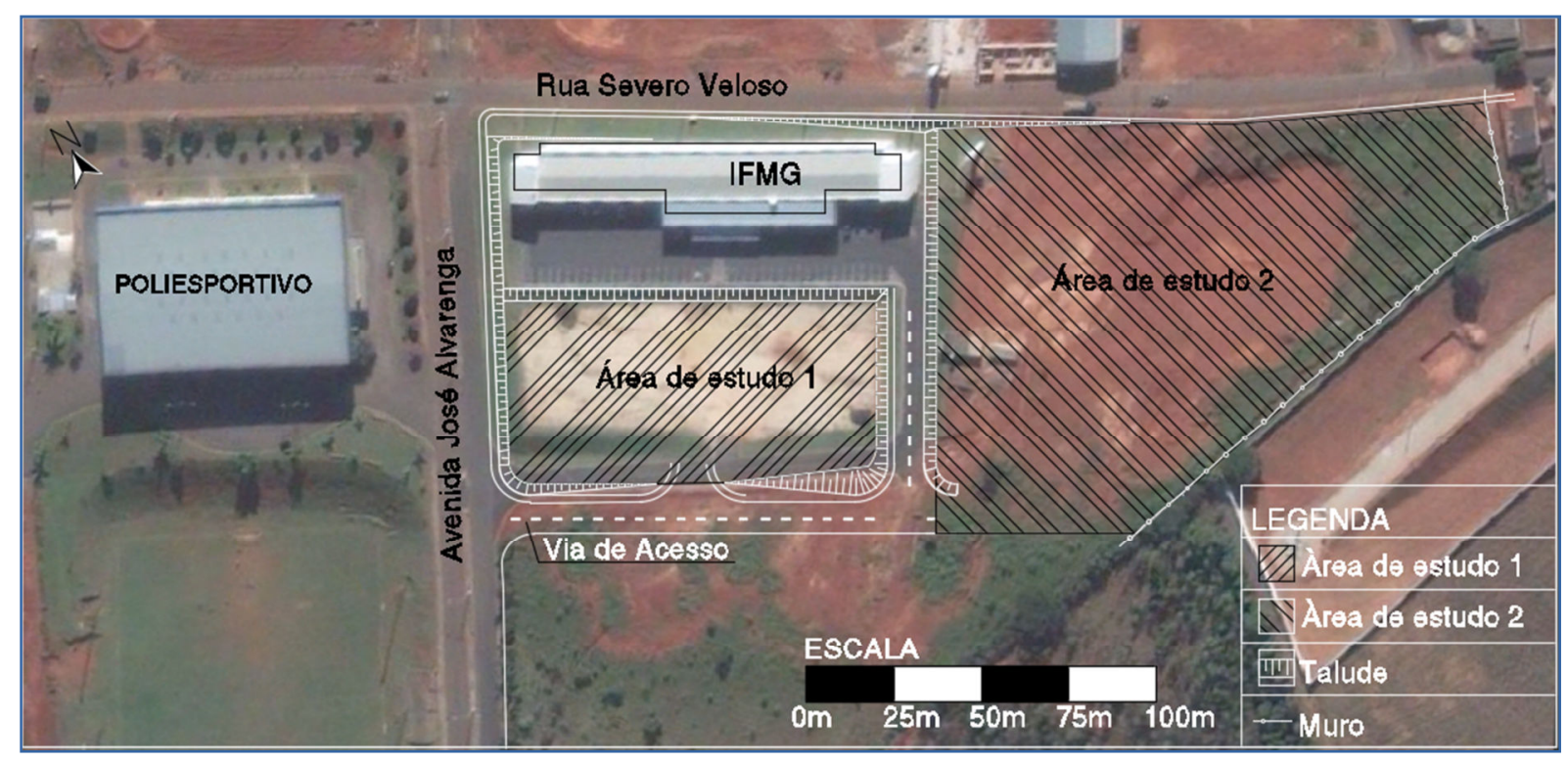

Figura 1 - Imagem aérea do terreno do IFMG - Campus Avançado Piumhi, em 2013, com detalhe das áreas de estudo

Fonte: Google Earth ${ }^{\mathrm{TM}}$, com adaptações. Acesso em: 15 out. 2015.

\subsubsection{Estratigrafia do Terreno}

Conforme entrevista semiestruturada $\mathrm{B}$, foram executadas sondagens a percussão no terreno, em agosto de 2007, as quais permitiram a obtenção de características do subsolo.

Segundo informações fornecidas nesta entrevista, a estratigrafia do terreno das áreas de estudo é marcada por duas camadas homogêneas de solo: a mais superficial, de coloração laranja avermelhada, é composta de silte argiloso e possui aproximadamente $6 \mathrm{~m}$ de espessura; a mais profunda, amarelada, é constituída de silte arenoso e apresenta boa capacidade de suporte; em ambas as camadas de solo, não foi identificada a presença de matacões e/ou pedregulhos.

Nas sondagens a percussão supracitadas, executadas no período de estiagem, não foi encontrado o lençol freático, tampouco o topo do maciço rochoso. No entanto, cabe ressaltar a existência de um poço tubular profundo com $27 \mathrm{~m}$ de comprimento, ao lado do prédio atual do Campus. 


\section{FORSCIENCE}

DANTAS, H. da S. et al. Estudo de viabilidade técnica da aplicação do método sísmica de refração para otimização de prováveis obras de ampliação do IFMG - Campus avançado Piumhi

\subsubsection{Histórico de terraplenagem}

Através da entrevista semiestruturada $\mathrm{B}$, foram obtidas informações a respeito dos serviços de terraplenagem destinados à construção das atuais instalações do Campus, que compreenderam escavação e aterro.

De acordo com a Figura 2 a seguir, as áreas de corte estão distribuídas nas porções central e leste do terreno. Na área de corte 1, a altura de escavação é variável, apresentando valor máximo em torno de $3 \mathrm{~m}$, à direita, que diminui gradativamente à esquerda, sendo nulo após cerca de $70 \mathrm{~m}$ de extensão em planta. $\mathrm{Na}$ área de corte 2, a altura de escavação também é variável, contendo valor máximo de aproximadamente $1,5 \mathrm{~m}$, à esquerda, que diminui gradualmente à direita, sendo nulo após cerca de $65 \mathrm{~m}$ de extensão em planta.

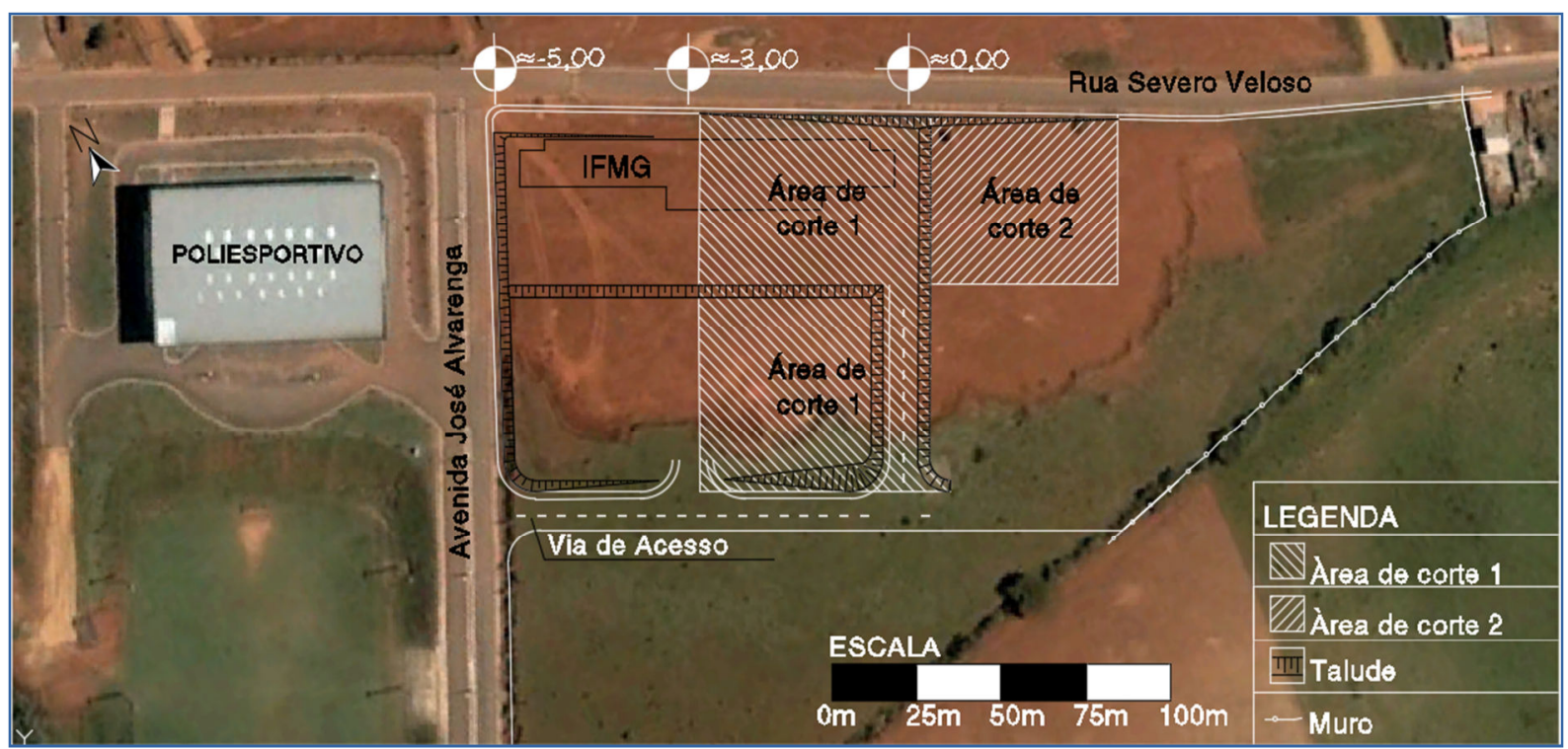

Figura 2 - Imagem aérea do terreno do IFMG - Campus Avançado Piumhi, em 2003, com detalhe das áreas de corte

Fonte: Google Earth ${ }^{\mathrm{TM}}$, com adaptações. Acesso em: 15 out. 2015.

A Figura 3 a seguir apresenta a distribuição da área de aterro, que está localizada na porção oeste do terreno. A altura de aterro é variável, apresentando valor máximo em torno de $6 \mathrm{~m}$, à esquerda, que diminui gradativamente à direita, sendo nulo após cerca de $60 \mathrm{~m}$ de extensão em planta. 


\section{FORSCIENCE}

DANTAS, H. da S. et al. Estudo de viabilidade técnica da aplicação do método sísmica de refração para otimização de prováveis obras de ampliação do IFMG - Campus avançado Piumhi

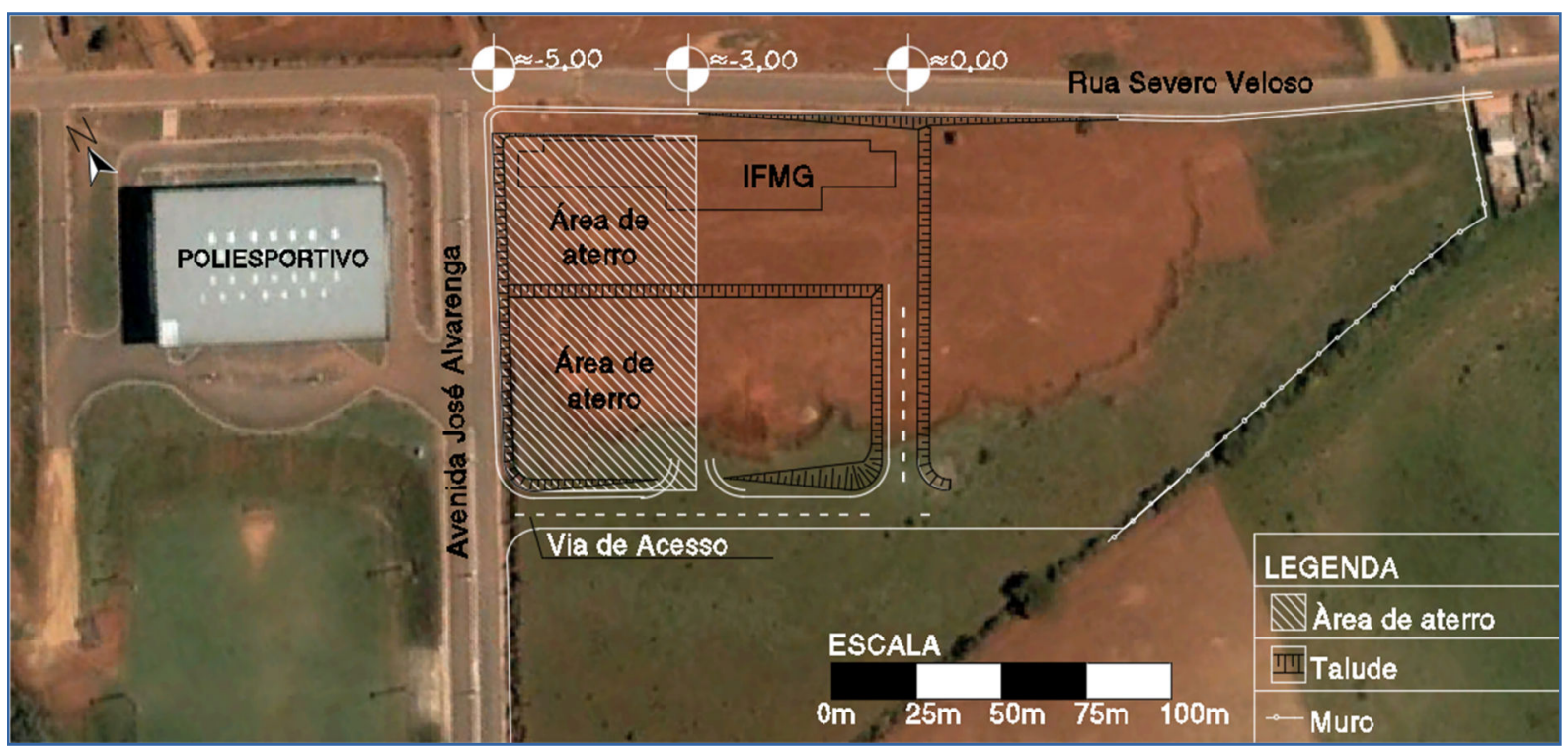

Figura 3 - Imagem aérea do terreno do IFMG - Campus Avançado Piumhi, em 2003, com detalhe da área de aterro

Fonte: Google Earth ${ }^{\mathrm{TM}}$, com adaptações. Acesso em: 15 out. 2015.

\subsubsection{Ocorrência de interferências e benfeitorias no terreno}

De acordo com a entrevista semiestruturada $\mathrm{B}$, não há registro de interferências subterrâneas ou superficiais.

À direita das atuais instalações do IFMG - Campus Avançado Piumhi, há um poço tubular profundo com cerca de $27 \mathrm{~m}$ de comprimento, localizado junto ao reservatório de água, conforme detalhado na Figura 4 a seguir. À frente deste, há um monumento que homenageia o Sr. Otacílio Gonçalves Tomé, empresário e ex-prefeito da cidade de Piumhi, concessor do atual terreno e das instalações do Campus.

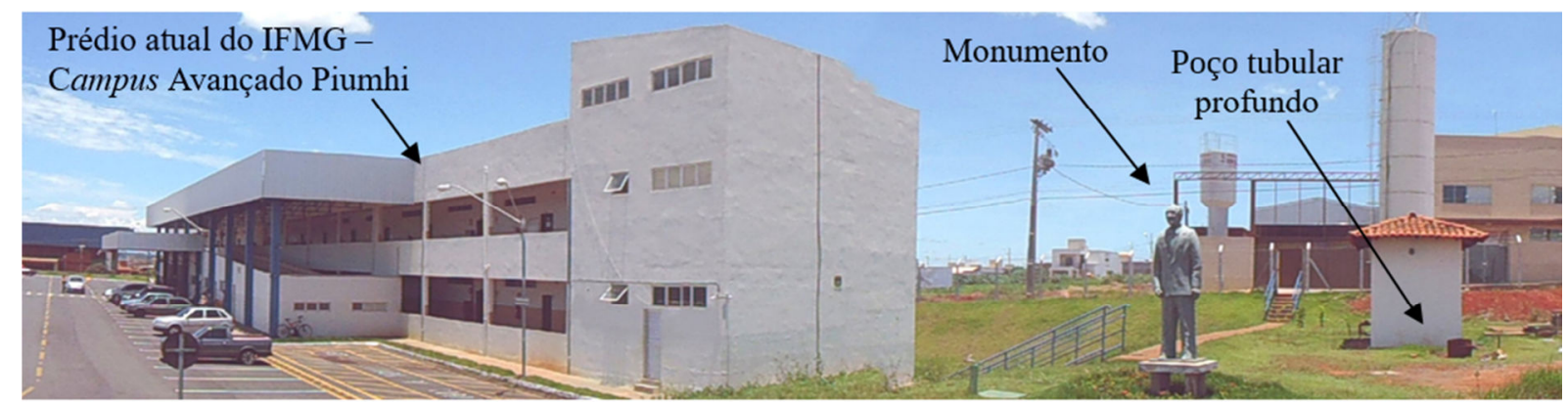

Figura 4 - Imagem do IFMG - Campus Avançado Piumhi, em outubro de 2015, com detalhe das benfeitorias. Fonte: Arquivo Pessoal (2015). 


\subsubsection{Prédio Atual}

A atual edificação do Campus apresenta área total construída de aproximadamente $3450 \mathrm{~m}^{2}$, distribuída em dois pavimentos, e contém nove salas de aula, nove salas destinadas ao setor administrativo, uma biblioteca, um auditório, quatro toaletes, um restaurante e seis laboratórios divididos nas seguintes disciplinas: Informática (dois laboratórios), Química Experimental, Física Experimental, Topografia e Desenho Técnico e Arquitetônico. O prédio está localizado em frente a um estacionamento pavimentado que possui 72 vagas para carros, 21 vagas para motocicletas e cerca de $2.450 \mathrm{~m}^{2}$.

De acordo com a entrevista semiestruturada B, na construção na edificação atual, foram utilizadas fundações do tipo estaca strauss ${ }^{8}$ com profundidade de assentamento que variou de seis a $14 \mathrm{~m}$. As estacas de maior comprimento foram executadas na área de aterro. Nas áreas de corte, foram executadas estacas de menor profundidade. De forma geral, foram utilizadas duas estacas por pilar, exceto em casos de maior esforço na estrutura, nos quais foram executadas três estacas por pilar.

\subsubsection{Natureza e finalidade das futuras edificações}

A ideia preliminar de expansão do Campus, conforme entrevista semiestruturada A, contempla a construção de uma instalação predial de dois pavimentos, com porte similar ao do prédio existente, destinada a laboratórios de prática de Construção Civil, Geotecnia, Materiais de Construção, Instalações Elétricas, Instalações Hidrossanitárias, Desenho Técnico e Arquitetônico, etc., bem como salas de aula e área arborizada de recreação e convivência.

\section{CONCLUSÃO}

É recomendado o uso da técnica de levantamento por sísmica de refração nas áreas onde provavelmente serão executadas obras de ampliação do IFMG - Campus Avançado Piumhi, em virtude das razões explicitadas a seguir.

É razoável admitir que a fundação de prováveis instalações do Campus possa ser profunda, atingindo profundidade de assentamento entre 6 e $14 \mathrm{~m}$, conforme fundação do

\footnotetext{
${ }^{8}$ Conforme NBR 6122: "Estaca executada por perfuração do solo com uma sonda ou piteira e revestimento total com camisa metálica, realizando-se o lançamento do concreto e retirada gradativa do revestimento com simultâneo apiloamento do concreto.” (ABNT, 2010).
}

ForSci.: r. cient. IFMG, Formiga, v. 4, n. 1, p. 63-81, jan./jun. 2016. 


\section{FORSCIENCE}

DANTAS, H. da S. et al. Estudo de viabilidade técnica da aplicação do método sísmica de refração para otimização de prováveis obras de ampliação do IFMG - Campus avançado Piumhi

prédio atual do referido Campus (ver entrevista semiestruturada B), pois aquelas provavelmente apresentarão porte similar a este, de acordo com a entrevista semiestruturada A. A técnica de sísmica de refração poderá apresentar, na subsuperfície estudada, profundidade de prospecção em torno de 30m, conforme entrevista semiestruturada $\mathrm{C}$, possibilitando, assim, a elaboração de um perfil praticamente contínuo das interfaces entre as camadas de solo e/ou rocha, dado este não fornecido pelas investigações diretas.

O método geofísico supracitado poderá contribuir para o mapeamento da camada de solo mais profunda identificada pelas investigações diretas, de cor amarela, constituída de silte arenoso, cujas propriedades mecânicas são adequadas ao assentamento da fundação de prováveis instalações, bem como do aterro, que possivelmente não apresenta boa capacidade de suporte, homogeneidade nem estabilidade, visto que não houve controle laboratorial de sua compactação, para evitar que nesta área seja feito o assentamento da fundação de obras de ampliação da infraestrutura do Campus (ver entrevista semiestruturada B).

A técnica de sísmica de refração poderá ainda identificar elementos que possam influenciar a execução de futuras obras, embora a entrevista semiestruturada B não tenha indicado a presença de interferências subterrâneas nas proximidades das áreas de estudo.

Adicionalmente, a provável ampliação da estrutura física do Campus aumentará o seu consumo de água. Tendo em vista que a água utilizada no Campus provém de um poço tubular profundo com cerca de $27 \mathrm{~m}$ de comprimento (ver entrevista semiestruturada B), a execução de novos poços seria uma alternativa razoável para suprir a nova demanda. $\mathrm{O}$ levantamento por sísmica de refração poderá contribuir para o mapeamento do lençol freático e, por consequência, para elaboração do projeto de tais poços.

Com base nas questões levantadas anteriormente, para orientar possíveis aplicações da técnica de sísmica de refração nas áreas de estudo, é proposta, na Figura 5 a seguir, uma programação de prospecção por sísmica de refração nas áreas de estudo. Cabe ressaltar que a mesma deverá ser confirmada em campo por meio de levantamentos preliminares. 


\section{FORSCIENCE}

DANTAS, H. da S. et al. Estudo de viabilidade técnica da aplicação do método sísmica de refração para otimização de prováveis obras de ampliação do IFMG - Campus avançado Piumhi

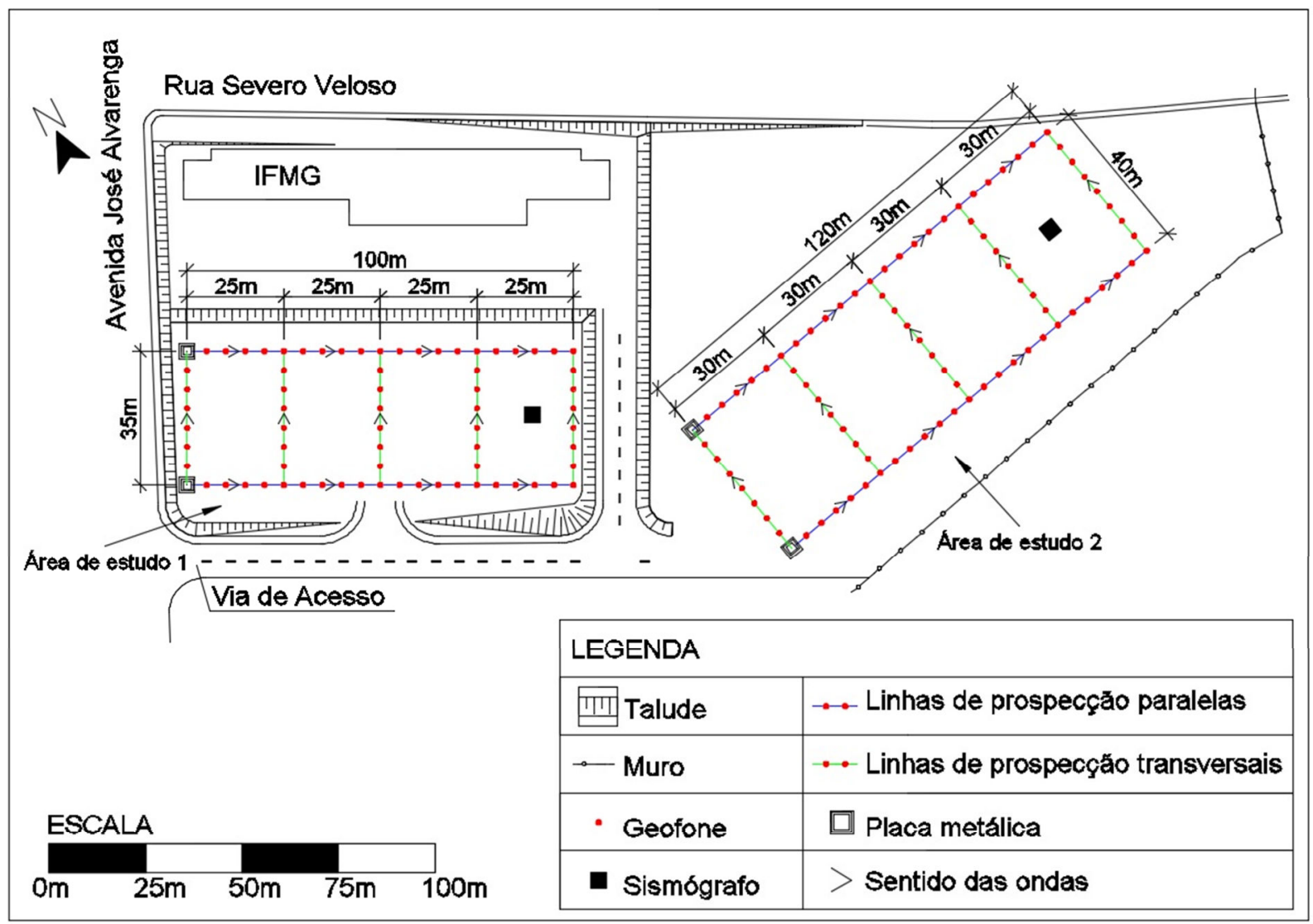

Figura 5 - Programação proposta de prospecção por sísmica de refração nas áreas de estudo Fonte: Arquivo pessoal (2015).

O levantamento proposto na Figura 5 encontra-se detalhado no Quadro 1 a seguir e no texto subsequente.

\begin{tabular}{|c|l|c|c|c|}
\hline $\begin{array}{c}\text { Área de } \\
\text { estudo }\end{array}$ & \multicolumn{1}{c|}{$\begin{array}{c}\text { Linha de } \\
\text { prospecção }\end{array}$} & $\begin{array}{c}\text { Número de } \\
\text { linhas }\end{array}$ & $\begin{array}{c}\text { Extensão } \\
\text { (metros) }\end{array}$ & $\begin{array}{c}\text { Quantidade de geofones } \\
\text { por linha }\end{array}$ \\
\hline \multirow{2}{*}{$\mathbf{1}$} & Paralela & 2 & 100 & 20 \\
& Transversal & 5 & 35 & 5 \\
2 & Paralela & 2 & 120 & 24 \\
& Transversal & 5 & 40 & 6 \\
\hline
\end{tabular}

Quadro 1 - Detalhamento da programação de prospecção.

Fonte: Arquivo pessoal (2015).

Sugere-se a utilização de geofones com 14 ou $40 \mathrm{~Hz}$ de frequência de operação, cravados no terreno a cada $5 \mathrm{~m}$ em planta, bem como o uso de impacto de uma marreta sobre placa metálica semienterrada para servir de fonte de ondas sísmicas, tendo em vista que esta fonte seria suficiente para atingir a profundidade de investigação desejada (em torno de $30 \mathrm{~m}$ ), sem causar danos às construções circunvizinhas, o que poderia ocorrer no emprego de outras 
DANTAS, H. da S. et al. Estudo de viabilidade técnica da aplicação do método sísmica de refração para otimização de prováveis obras de ampliação do IFMG - Campus avançado Piumhi

fontes sísmicas, tais como queda de peso e explosivos (ver entrevista semiestruturada C; AZEVEDO, 2010).

\title{
TECHNICAL VIABILITY STUDY OF SEISMIC REFRACTION METHOD APPLICATION IN ORDER TO OPTIMIZE PROBABLE FUTURE EXPANSION WORKS OF THE IFMG-CAMPUS AVANÇADO PIUMHI
}

\begin{abstract}
The study of soil behavior is very important for Civil Engineering, since any building interacts with the Earth's surface. Thus, the geophysical method called seismic refraction can provide relevant information to the systemic knowledge of subsurface, complementing the direct investigation data, which are specific to the prospected point. This work aims to study the technical viability of applying seismic refraction method in order to optimize probable future expansion works of the IFMG - Campus Avançado Piumhi. Information were obtained about this geophysical method application and features of subsoil, the current building and probable installations of the campus. These data were analyzed qualitatively and provided support to the technical viability study. It was concluded that the seismic refraction method application in the study areas is technically viable and may contribute to elaboration of a practically continuous soil profile as well as to the water table mapping. It was recommended a prospecting program by this method in the study areas in order to guide possible seismic refraction applications on site.
\end{abstract}

Keywords: Seismic Refraction. Indirect Prospection Method. Technical Viability.

\section{REFERÊNCIAS}

ASSOCIAÇÃO BRASILEIRA DE NORMAS TÉCNICAS. NBR 6122: projeto e execução de fundações: termos e definições. Rio de Janeiro: ABNT, 2010.

AZEVEDO, P. A. de; ROCHA, M. P. Estudo do método geofísico de sísmica de refração com aplicação no futuro trecho norte do metrô de Brasília. 2010. Disponível em: $<$ https://www.ucb.br/sites/100/118/TCC/2\%C2\%BA2010/TCCPAULOARAUJO.pdf $>$. Acesso em: 10 out. 2015.

BARSÉ, L. et al. Determinação da espessura do manto de intemperismo utilizando sísmica de refração rasa na área de Seival - RS. 2010. Disponível em: $<$ http://www.ufrgs.br/rede-carvao/Sess\%C3\%B5es_C1_C2_C3/C3_ARTIGO_03.pdf $>$. Acesso em: 15 nov. 2015.

CAPUTO, H. P. Mecânica dos solos e suas aplicações: fundamentos. 6. ed. Rio de Janeiro: LTC, 2014. v. 1.

CHIOSSI, N. J. Geologia de engenharia. 3. ed. São Paulo: Oficina de Textos, 2013. 
FLICK, U. Desenho da pesquisa qualitativa. Porto Alegre: Bookman, 2009.

. Uma introdução à pesquisa qualitativa. Tradução de Sandra Netz. 2. ed. Porto Alegre: Bookman, 2004.

HERZIG, R. L. Integração das técnicas de refração e reflexão sísmica rasa aplicada ao estudo de barragens-UHE Piraju II. Revista Brasileira de Geofísica, São Paulo, v. 22, n. 2, maio/ago. 2004.

INSTITUTO BRASILEIRO DE GEOGRAFIA E ESTATÍSTICA. Censo Demográfico 2010: resultados do universo. 2010. Disponível em: <http://cod.ibge.gov.br/GZJ >. Acesso em: 20 out. 2015.

KEAREY, P.; BROOKS, M.; IAN, H. Geofísica de exploração. Tradução de Maria Cristina Moreira Coelho. São Paulo: Oficina de Textos, 2009.

SHULL, F. et al. Knowledge-sharing issues in experimental software engineering. Empirical Software Engineering, v. 9, p. 111-137, mar. 2004.

TEIXEIRA, W. L. E. Um estudo das condições de percolação e estabilidade em barragens de terra mediante métodos geofísicos: caso do dique de Sant Llorenç de Montgai-Espanha. 2013. 168f. Tese (Doutorado em Geodinâmica e Geofísica)- Universidade Federal do Rio Grande do Norte, Natal, RN, 2013. Disponível em: <http://repositorio.ufrn.br/jspui/handle/ 123456789/18368>. Acesso em: 20 nov. 2015. 
APÊNDICE A - Entrevista Semiestruturada Aplicada Prof. Humberto Coelho de Melo. Piumhi/MG.

INSTITUTO FEDERAL

MINAS GERAIS

Campus Avançado Piumhi
Instituto Federal de Educação Ciência e Tecnologia de Minas

Gerais Campus Avançado Piumhi

Curso: Bacharelado em Engenharia Civil

Turma 2015/1

\section{ENTREVISTA SEMIESTRUTURADAA}

Esta entrevista semiestruturada é parte integrante da pesquisa “ESTUDO DE VIABILIDADE TÉCNICA DE APLICAÇÃO DO MÉTODO DE SÍSMICA DE REFRAÇÃO PARA OTIMIZAÇÃO DE PROVÁVEIS OBRAS DE AMPLIAÇÃO DO IFMG - CAMPUS AVANÇADO PIUMHI", desenvolvida pelos estudantes Marina Vieira Funchal Guimarães e Hiago da Silva Dantas, sob orientação do Professor Felipe Silva Alves e tem por objetivo coletar informações para o referido trabalho;

IMPORTANTE: as informações coletadas serão utilizadas exclusivamente para fins de pesquisa acadêmica.

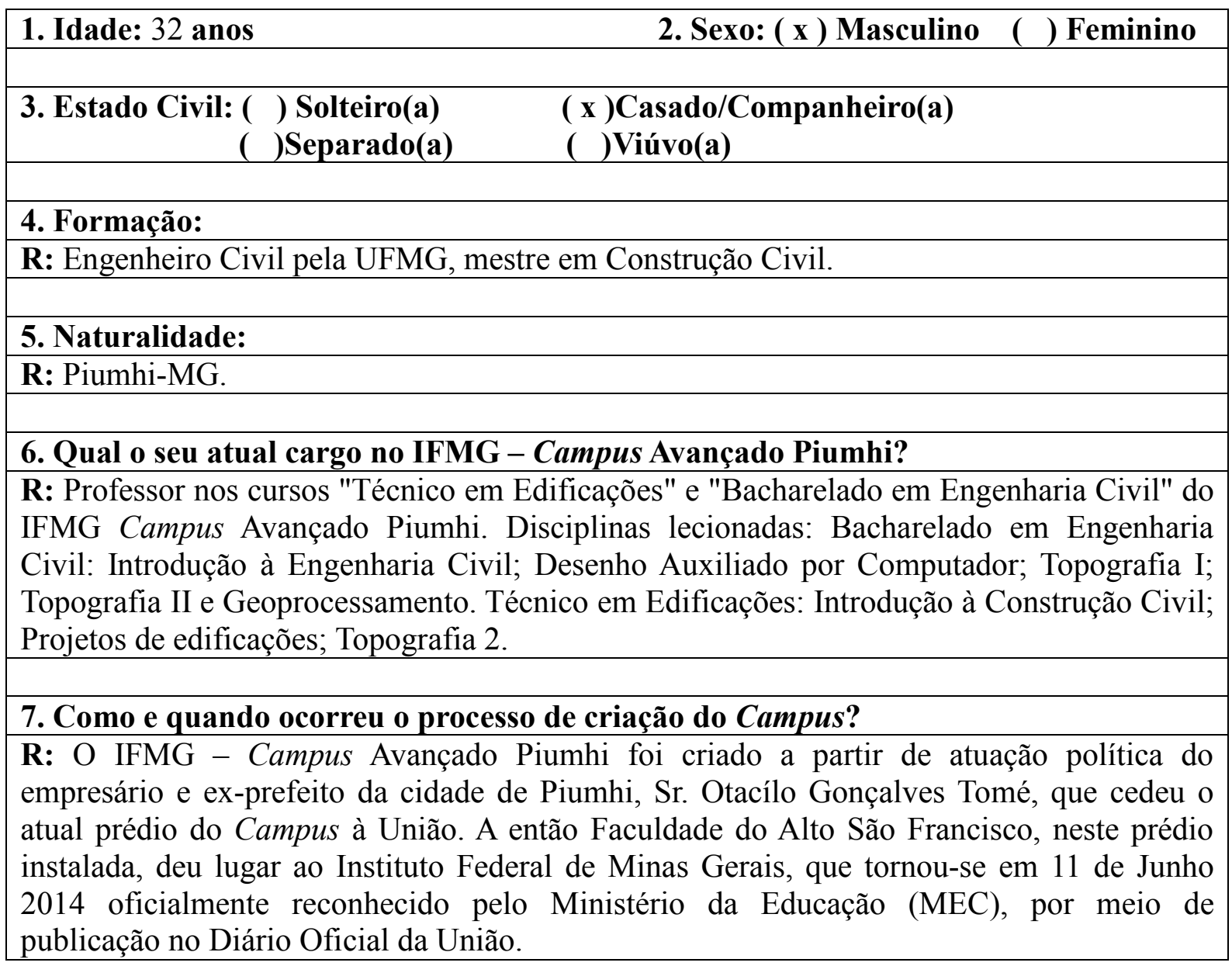




\section{FORSCIENCE}

DANTAS, H. da S. et al. Estudo de viabilidade técnica da aplicação do método sísmica de refração para otimização de prováveis obras de ampliação do IFMG - Campus avançado Piumhi

8. Como são distribuídas as instalações do prédio atual?

R: Essas informações são encontradas com detalhes no Projeto Pedagógico de Curso (PPC).

9. A infraestrutura do prédio atual é suficiente para atender a demanda futura dos cursos ofertados pelo Campus?

R: Sim, a infraestrutura do prédio atual atende a demanda dos cursos atualmente ofertados. No entanto, a médio e longo prazo, os laboratórios são as principais carências da infraestrutura o Campus. Como por exemplo: laboratório de prática de construção, informática, física, química, materiais de construção e hidráulica, etc. Estes laboratórios são essenciais para atender as questões de ensino e projetos de extensão e pesquisa.

10. Quais as ideias preliminares de obras de ampliação da infraestrutura do Campus?

R: Adequar os laboratórios já existentes e instalar novos laboratórios de modo a adequar às exigências do MEC para o curso. Para tanto são necessárias áreas maiores para instalar laboratórios, como por exemplo, de hidráulica e materiais de construção. Com desejo de implantar o curso técnico integrado algumas infraestruturas devem ser melhoradas, tais como, sala de aula e laboratórios adequados, bem como, a construção de área poliesportiva.

11. Qual a possível localização de prováveis futuras edificações?

R: $\mathrm{Na}$ área à direita do Campus.

12. Qual seria o porte de prováveis futuras edificações?

R: Área construída seria de cerca de $1500 \mathrm{~m}^{2}$ divididos em dois pavimentos.

Piumhi, 08 de junho de 2015

Humberto Coelho de Melo

Engenheiro Civil 
DANTAS, H. da S. et al. Estudo de viabilidade técnica da aplicação do método sísmica de refração para otimização de prováveis obras de ampliação do IFMG - Campus avançado Piumhi

APÊNDICE B - Entrevista Semiestruturada Aplicada ao Sr. Nivaldo Alves de Oliveira, Piumhi/MG.

INSTITUTO FEDERAL
MINAS GERAIS Instituto Federal de Educação Ciência e Tecnologia de Minas Gerais Campus Avançado Piumhi

Curso: Bacharelado em Engenharia Civil

Turma 2015/1

\section{ENTREVISTA SEMIESTRUTURADA B}

Esta entrevista semiestruturada é parte integrante da pesquisa "ESTUDO DE VIABILIDADE TÉCNICA DE APLICAÇÃO DO MÉTODO DE SÍSMICA DE REFRAÇÃO PARA OTIMIZAÇÃO DE PROVÁVEIS OBRAS DE AMPLIAÇÃO DO IFMG - CAMPUS AVANÇADO PIUMHI", desenvolvida pelos estudantes Marina Vieira Funchal Guimarães e Hiago da Silva Dantas, sob orientação do Professor Felipe Silva Alves e tem por objetivo coletar informações para o referido trabalho;

IMPORTANTE: as informações coletadas serão utilizadas exclusivamente para fins de pesquisa acadêmica.

\begin{tabular}{|c|}
\hline 2. Sexo: ( $x$ ) Masculino ( ) Feminino \\
\hline $\begin{aligned} & \text { 3. Estado Civil: ( ) Solteiro(a) } \text { ( x )Casado/Companheiro(a) } \\
& \text { ( )Separado(a) } \text { ( )Viúvo(a) } \\
&\end{aligned}$ \\
\hline 4. Formação: \\
\hline R: Engenheiro Civil formado em 1985 pela FEP, Passos/MG. \\
\hline 5. Naturalidade: \\
\hline R: Piumhi-MG \\
\hline 6. Quem foi o responsável técnico da execução das obras? \\
\hline R: Nivaldo Alves de Oliveira. \\
\hline 7. Qual a data de início e término das obras? \\
\hline R: O estudo de viabilidade e projetos ocorreram em 2007 e as obras foram de 2008 à 2009. \\
\hline $\begin{array}{l}\text { 8. Quais investigações geotécnicas foram realizadas no terreno? Qual(is) empresa(s) a } \\
\text { executou? Há documentos dessas prospecções? }\end{array}$ \\
\hline R: Foi executada sondagem à percussão pela Empresa COPLAN - Piumhi. \\
\hline 9. Qual a estratigrafia do terreno? \\
\hline $\begin{array}{l}\text { R: O solo é homogêneo, pouco variável e de grande profundidade, este é composto por } \\
\text { duas camadas principais: a mais superficial de coloração laranja avermelhado apresenta } \\
\text { características de silte argiloso, esta camada tem aproximadamente } 6 \mathrm{~m} \text { de profundidade; a } \\
\text { segunda, de cor amarela, é composta de silte arenoso e apresentou propriedades mecânicas } \\
\text { adequadas ao apoio das fundações. A prospecção do terreno não atingiu o lençol freático, no } \\
\text { entanto, é importante ressaltar que a mesma foi realizada em agosto, no período de } \\
\text { estiagem. Posteriormente, durante a perfuração do poço artesiano presente no Campus, foi }\end{array}$ \\
\hline
\end{tabular}




\section{FORSCIENCE}

DANTAS, H. da S. et al. Estudo de viabilidade técnica da aplicação do método sísmica de refração para otimização de prováveis obras de ampliação do IFMG - Campus avançado Piumhi

encontrada água à cota de $27 \mathrm{~m}$. O topo do maciço rochoso não foi encontrado, bem como a presença de matacões e pedregulhos.

10. Como se procedeu a terraplenagem?

R: Os trabalhos de terraplenagem compreenderam áreas de escavação e aterro. $\mathrm{Na}$ área do atual prédio houve cortes de $3,5 \mathrm{~m}$ na porção Leste com aproximadamente $50 \mathrm{~m}$ de extensão. $\mathrm{Na}$ metade à Noroeste da área houve aterro de $6 \mathrm{~m}$ com aproximadamente $60 \mathrm{~m}$ de comprimento. No terreno atualmente destinado a estacionamento (não pavimentado) houve aterro de $6 \mathrm{~m}$. Não houve controle laboratorial da compactação do aterro.

11. Qual a fundação executada?

R: Foi executada fundação do tipo Estaca Strauss, que variou de 6 a 14m de profundidade. As mais profundas ocorreram nas áreas de aterro. Geralmente foram utilizadas duas estacas por pilar, exceto em alguns casos de maior esforço na estrutura em que foram executadas três estacas por pilar.

12. Houve alguma dificuldade na execução da obra? Quais?

R: Não.

13. É de seu conhecimento a existência de interferências no subsolo?

R: Não.

Piumhi, 16 de Outubro de 2015

Nivaldo Alves de Oliveira Engenheiro Civil 
DANTAS, H. da S. et al. Estudo de viabilidade técnica da aplicação do método sísmica de refração para otimização de prováveis obras de ampliação do IFMG - Campus avançado Piumhi

\section{APÊNDICE C - Entrevista Semiestruturada Aplicada ao Sr. Wagner França Aquino, Geofísico da GPR Geofísica Ltda., São Paulo/SP}

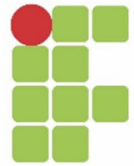

INSTITUTO FEDERAL

MINAS GERAIS

Campus Avançado Piumhi.

Instituto Federal de Educação Ciência e Tecnologia de Minas

Gerais Campus Avançado Piumhi

Curso: Bacharelado em Engenharia Civil

Turma 2015/1

\section{ENTREVISTA SEMIESTRUTURADA C}

Esta entrevista semiestruturada é parte integrante do "ESTUDO DE VIABILIDADE TÉCNICA DE APLICAÇÃO DO MÉTODO DE SÍSMICA DE REFRAÇÃO PARA OTIMIZAÇÃO DE PROVÁVEIS OBRAS DE AMPLIAÇÃO DO IFMG - CAMPUS AVANÇADO PIUMHI", desenvolvida pelos estudantes Hiago da Silva Dantas e Marina Vieira Funchal Guimarães, sob orientação do Professor Felipe da Silva Alves e tem por objetivo coletar informações para o referido trabalho;

IMPORTANTE: as informações coletadas serão utilizadas exclusivamente para fins de pesquisa acadêmica.

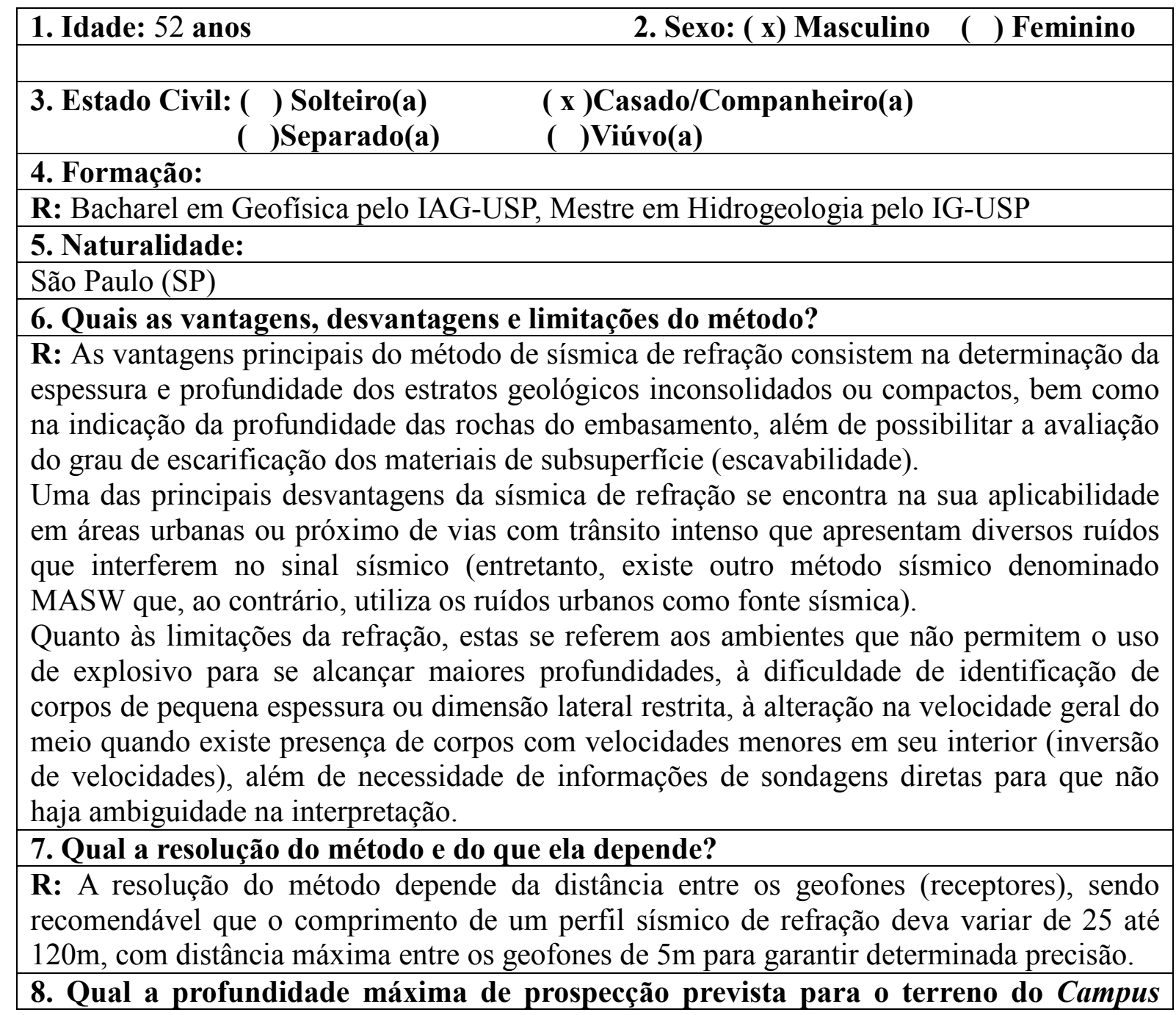


DANTAS, H. da S. et al. Estudo de viabilidade técnica da aplicação do método sísmica de refração para otimização de prováveis obras de ampliação do IFMG - Campus avançado Piumhi

Avançado Piumhi, utilizando-se o método de sísmica de refração? O que influencia no alcance da prospeç̧ão?

R: A profundidade máxima deverá estar correlacionada ao tipo de serviço que será efetuado na área, sendo que para obras de ampliação e novas construções, como é o caso, a profundidade de interesse deve ser de $30 \mathrm{~m}$ no máximo. Neste caso, a sísmica de refração utilizando como fonte de sinal um impacto de martelo em placa de metal possui este alcance em subsuperfície, sem necessidade de outras fontes (queda de peso ou explosivos).

\section{Quais as aplicações do método relacionadas ao artigo?}

R: Como indicado anteriormente, a aplicação da sísmica contribuiria na coleta de informações quanto à determinação da espessura e profundidade dos estratos geológicos inconsolidados ou compactos, bem como na eventual indicação da profundidade do embasamento, além de possibilitar a avaliação do grau de escarificação dos materiais de subsuperfície (escavabilidade).

10. Quais as formas de aplicação do método? Dentre elas, qual seria a mais indicada para o artigo?

R: O levantamento de sísmica de refração deveria ser desenvolvido a partir da realização de diversos perfis na área de interesse, sendo executadas linhas sísmicas longitudinais e transversais com intuito de se cobrir todos os quadrantes dos locais a serem investigados.

$\mathrm{O}$ arranjo de campo se constituiria em cravar os geofones na superfície do solo ao longo do perfil que se deseja amostrar e, a partir de um disparo proveniente de uma fonte sísmica (impacto de marreta em placa metálica), fossem efetuadas medições do tempo de trânsito da onda da fonte até o geofone (receptor), com coleta dessas informações no sismógrafo (registrador) para processamento dos dados e interpretação.

Posteriormente, na etapa de processamento de dados, é realizada a identificação da onda refrata e nos registros dos tempos de trânsito nos geofones, sendo calculadas as velocidades de propagação da onda no meio investigado, e obtendo-se, assim, sua espessura, permitindo a elaboração de modelos de geofísicos de subsuperfície.

11. Qual seria a programação de investigação por sísmica de refração (detalhamento da prospecção: linhas de prospecção, dimensionamento dos geofones, etc.) mais indicada para o artigo?

R: Como anteriormente descrito, seria necessária a execução de linhas transversais e longitudinais nas áreas de interesse, sendo que a quantidade e o posicionamento desses perfis dependem das dimensões e acessibilidade dos locais a serem investigados, de preferência em pontos sem pavimento para cravação dos geofones. Além disso, é recomendável que cada linha sísmica possua um comprimento de $120 \mathrm{~m}$, com adoção de geofones de $14 \mathrm{~Hz}$ de frequência de operação e tenham uma distância de separação de $5 \mathrm{~m}$.

São Paulo, 14 de Outubro de 2015.

Wagner França Aquino

Geofísico

Recebido em: 21/09/2015

Aprovado em: 20/02/2016

Publicado em: 05/07/2016 